\title{
Laparoscopic low anterior resection and transanal pull-through for low rectal cancer: A case report
}

\author{
HMKB Herath ${ }^{1}$, RMIM Senevirathne ${ }^{1}$, WUC Alwis ${ }^{1}$, KB Galketiya $^{2}$ \\ ${ }^{\prime}$ Teaching Hospital Peradeniya, Sri Lanka \\ ${ }^{2}$ Department of Surgery, Faculty of Medicine, University of Peradeniya, Sri Lanka
}

\section{Introduction}

Surgical resection of lower rectal tumours is often considered to be technically challenging especially when the anal sphincter mechanism needed to be spared to avoid lifelong colostomy. Stapling has made anastomosis below peritoneal reflection easier. However with very low tumours stapling too may be difficult due to short rectal stump. An alternative is to perform a transanal pull through and a colo-anal anastomosis. Use of laparoscopic resection in these cases reduces the morbidity associated with open resections. We report a case of successful use of tansanal pull-through technique to avoid diverting stoma in resection of a lower rectal tumour.

\section{Case History}

59 year old female presented with altered bowel habits and fresh per rectal bleeding for two months duration. Upon digital rectal examination she had an irregular growth at 6 O'clock position of the lower rectum about $5 \mathrm{~cm}$ from the anal verge. Biopsy and histopathological examination of the lesion revealed a moderately differentiated adenocarcinoma. She underwent a CT scan of the chest, abdomen and pelvis which showed a lower rectal tumour extending to a length of about $8 \mathrm{~cm}$ proximally with no evidence of invasion into mesorectal fascia (Figure 1). There were enlarged mesorectal lympnodes and metastatic deposits in segment IV and VIII of the liver and in both lung fields (Stage T3N2M1). Her pretreatment carcinoembryonic antigen (CEA) level was $2.72 \mathrm{ng} \backslash \mathrm{ml}$ (Normal $<3$ $n g \backslash \mathrm{ml})$.

F o 11 ow ing ne o a d u vant chemoradiotherapy she underwent laparoscopic low anterior resection and transanal pull-through procedure. Dissection around the mesorectum and mobilization of proximal colon up to splenic flexure was carried out laparocopically. Perineal stage of the surgery began with circumferential mucosectomy at the dentate line and dissection up to the level of abdominal dissection. Total mesorectal excision of the tumour was completed and transanal pull though of the rectum containing the tumour and sigmoid colon was carried out. After excising the tumour with more than $5 \mathrm{~cm}$ proximal margin, proximal colon was attached to the dentate line with interrupted non-absorbable sutures leaving a free stump of about $10 \mathrm{~cm}$ outside the anus (figure 2).

Initial postoperative period was unremarkable and daily inspection of the external colonic segment was done. By postoperative day 4 , intravenous fluids 
HMKB Herath, RMIM Senevirathne, WUC Alwis, KB Galketiya - Laparoscopic low anterior resection and transanal pull-through for low rectal cancer: A case report

were omitted and she was on semisolid diet. On postoperative day 7 external colonic segment was trimmed off under anaesthesia. Subsequent recovery was uneventful and she had retained her faecal continence. Upon histopathological examination of the specimen, the distal resection margin was clear of tumour by $5 \mathrm{~mm}$.

\section{Discussion}

Surgical resection is an essential component in the treatment of rectal cancers and the two main surgical procedures that are being used today are the anterior resection (AR) and abdominoperineal resection with permanent colostomy. AR carries the benefit of avoiding lifelong stoma without compromising the oncological outcome (1). The colo-rectal anastomosis in AR is often difficult when the tumour is located lower down in the rectum but the introduction of stapling devices has allowed to take off the difficulties of hand anastomosis. However with very low tumours stapling too may be difficult. In this situation transanal pull through and colo-anal anastomosis is an alternative. This technique was first described in 1932 by Babcock (2). It has the benefit of avoiding temporary de-functioning stoma which can result in minor and major complications in about $10 \%$ of the cases $(3,4)$.

The use of laparoscopy also has increased over the past decade for patients with colonic cancers and several trials have demonstrated the equivalent short- and long-term oncological outcomes for laparoscopic and open approaches $(5,6)$ with the added advantage of low morbidity compared to open approach (7). When combined with laparoscopy, transanal pull through technique will result in minimal scarring since there is no stoma creation while the specimen is extracted through the anus.

The patient under discussion had disseminated disease and the treatment was primarily palliative with the aim of improving survival as well. In this situation even with a shorter tumour free resection margin avoiding a permanent stoma will be beneficial. As the tumour was too low for stapling we performed a transanal pull through and colo-anal anastomosis. With the use of laparoscopic dissection the operative morbidity became less as there were no major abdominal incisions. Its magnified clear vision allowed us to carry out the dissection right down through the pelvic diaphragm which is an essential step for an easy perineal dissection via anus.

\section{Conclusion}

In surgical treatment of tumours in lower rectum laparoscopic low anterior resection and transanal pull-through is a feasible procedure. 
HMKB Herath, RMIM Senevirathne, WUC Alwis, KB Galketiya - Laparoscopic low anterior resection and transanal pull-through for low rectal cancer: A case report

\section{References}

1. Cavaliere F, Pemberton JH, Cosimelli M, Fazio VW, Beart RW Jr. Coloanal anastomosis for rectal cancer.Long-term results at the Mayo and Cleveland Clinics. Dis Colon Rectum 1995 Aug;38(8):80712

2. Bab cock WW. Operative treatment of carcinoma of the rectosigmoid. Surg Gynecol Obst. 1932;55:627-34,

3. Ed wards DP, Lepping ton-Clarke A, Sex ton R, et al. Stoma-related complications are more frequent after trans verse colostomy than loop ileostomy: a pro spective randomized clinical trial. Br J Surg. 2001;88:360-363

4. Law W, Chu W, Choi HK. Randomized clinical trial comparing loop ileostomy and loop transverse colostomy for faecal diversion following total mesorectal excision. Br J Surg. 2002;89:704-708.
5. Guillou PJ, Quirke P, Thorpe H, Walker J, Jayne DG, Smith AM, et al. Short-term endpoints of conventional versus laparoscopic assisted surgery in patients with colorectal cancer (MRC CLASICC trial): multicentre, randomised controlled trial. Lancet. 2005 May 14-20;365(9472):1718-1726. PubMed PMID: 15894098.

6. Bagshaw PF, Allardyce RA, Frampton CM, Frizelle FA, Hewett PJ, McMurrick PJ, et al. Long-term outcomes of the australasian randomized clinical trial comparing laparoscopic and conventional open surgical treatments for colon cancer: the Australasian Laparoscopic Colon Cancer Study trial. Annals of surgery. 2012 Dec;256(6):915-919. PubMed PMID: 23154392

7. Wu W-X, et al. Laparoscopic versus conventional open resection of rectal carcinoma: a clinical comparative study. World J Gastroenterology 2004:10(8):1167-1170.

\section{Figures}

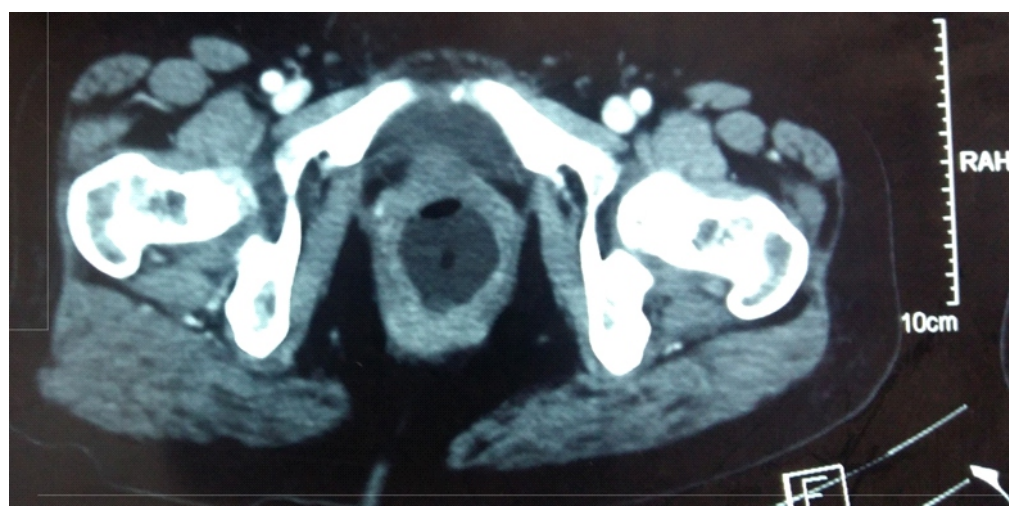

Figure 1: Contrast enhanced CT scan of the Pelvis showing eccentric wall thickening of the rectum 
HMKB Herath, RMIM Senevirathne, WUC Alwis, KB Galketiya - Laparoscopic low anterior resection and transanal pull-through for low rectal cancer: A case report

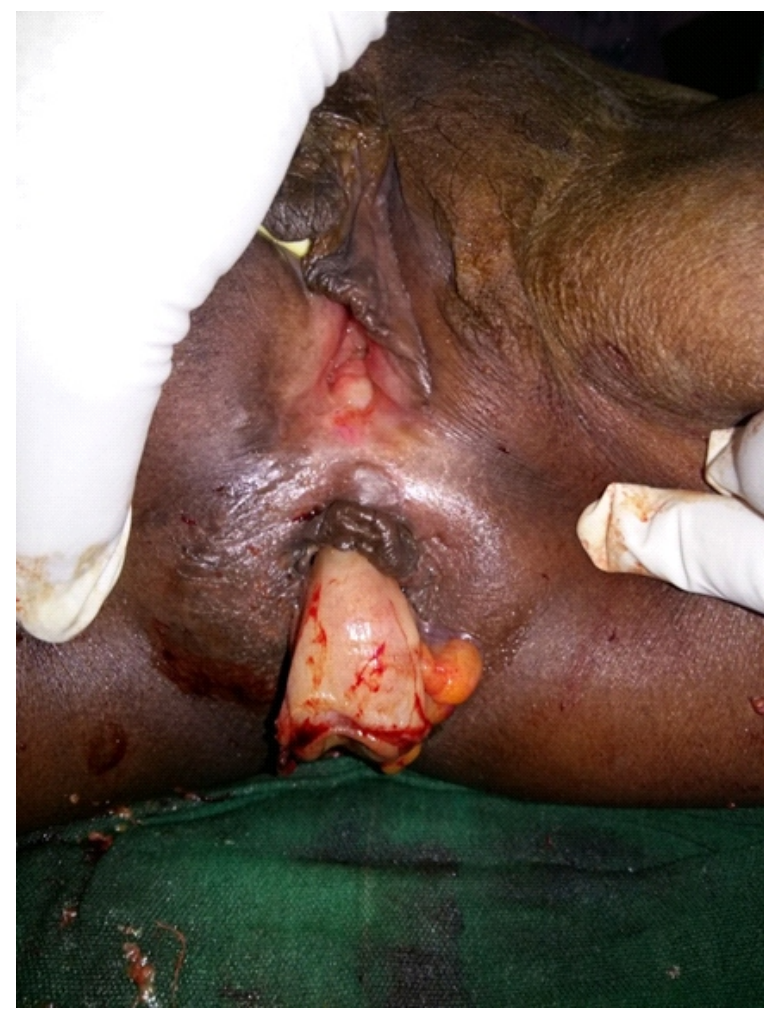

Figure 2: Distal colonic stump protruding out of the anus after surgery 